\title{
Influencia del medio ambiente en los materiales de construcción
}

\author{
JOSE M. FERnANDez PARIS, Jefe de la Sección de Cementos y Ensayos Químicos del Instituto Técnico de Materiales \\ y Construcción \\ INTEMAC, S. A. Madrid
}

Los materiales de naturaleza pétrea, procedentes de las rocas naturales, pueden considerarse como los materiales de construcción más primitivos, utilizándose en la antigüedad clásica como parte integrante de las estructuras y en paramentos y conjuntos nobles.

Durante la última centuria, y como consecuencia obligada de la industrialización de los conglomerantes hidráulicos, ha tomado carta de naturaleza un nuevo material: el hormigón.

Desde el punto de vista material e, incluso estructural, puede considerarse al hormigón como una piedra artificial de características físico-químicas bastante definidas (1).

La durabilidad de las piedras naturales ha sido proverbial, hasta el punto de que los vocablos "piedra" y "roca" se han estimado como sinónimos de resistencia en el lenguaje coloquial.

No obstante, esta teoría se va desvaneciendo en la actualidad, ya que la Geología moderna considera que los distintos minerales que componen las rocas están en un continuo proceso de evolución natural, tratando, en todo momento, de adaptarse a las condiciones del medio ambiente que las rodea en la superficie de la Tierra.

Una vez más de forma inexorable las leyes de la Termodinámica rigen las reacciones geológicas, transformándose los minerales existentes en otros de mayor estabilidad frente a los agentes del medio ambiente que los rodea.

La generalidad de las rocas que afloran a la superficie de la Tierra, se han consolidado en el interior a temperaturas y presiones mucho más elevadas, que las que les ofrece su nuevo ambiente y, por consiguiente, evolucionarán para acoplarse "lo más cómodamente posible" en este extraño "habitat".

La evolución de los materiales pétreos puede considerarse como una readaptación de los minerales que los integran al medio ambiente que los rodea. La presencia del oxígeno atmosférico favorece los procesos de oxidación y la humedad los de hidratación y disolución.

Ciertos procesos ambientales transcurren con lentitud, pero otros son rápidos e, incluso, expansivos, pudiendo originar daños de consideración.

Como norma general puede considerarse que los feldespatos y silicatos ferromagnesianos se transforman en arcillas, mientras que la mica y el cuarzo permanecen inalterados. 
El hormigón, material pétreo de características físicas más pobres que las rocas, es evidente que sufrirá también un proceso de evolución ambiental análogo al descrito.

Casi inmediatamente después de la construcción de las primeras obras con cemento, se comenzaron a observar los daños y desperfectos que sufrían (2). Numerosos investigadores han centrado sus esfuerzos en el estudio y comprobación de la agresividad de este material, llegando a constituir hoy día una rama primordial, en la química de los materiales de construcción, la durabilidad del hormigón.

En el Coloquio Internacional de Praga de la RILEM se admitió, no sin ciertas reservas, que una obra de hormigón no dura más de 50 años en condiciones normales de agresión, y no más de 30 años en medios agresivos, como aguas selenitosas o marinas (3).

Independientemente de esta opinión existen ejemplos de hormigones durables, correctamente ejecutados, que reprimen el pesimismo excesivo.

Los estudios e investigaciones sobre la posible agresividad a los hormigones se ha centrado en un conjunto de acciones aisladas (4): acción de los sulfatos; hielo y deshielo: aguas blandas; ácidos; cristalización de sales; reactividad de los áridos, etc. Sin considerar la importancia del ambiente atmosférico actual.

La denominada "alteración de la piedra" es ahora precisamente un fenómeno que preocupa a los técnicos de la construcción y, no es menos cierto, que durante los 75 años de esta centuria, el proceso de alteración de los materiales pétreos - tanto rocas, como hormigones- ha aumentado de forma alarmante.

La degradación de numerosos monumentos artísticos se ha producido con una intensidad inusitada en los centros urbanos e industriales, teniendo que recurrirse a la ayuda de ciertos organismos estatales o a la fundación de patronatos, encargados de su restauración.

Cuando se trata de monumentos arquitectónicos antiguos, lógicamente, no cabe más que aceptar el hecho consumado y tratar de restaurar; pero en las edificaciones actuales no debe hablarse de restaurar, sino de prevenir y, mejor aún, de proyectar bien.

Si las rocas, material evidentemente más estable que los silicatos y aluminatos cálcicos artificiales, que forman el conglomerado de hormigón, no son capaces de resistir en el entorno ambiental de las ciudades modernas, mucho menos lo soportará el hormigón, con cualidades físicas más pobres.

Se podría argumentar que ciertos elementos estructurales no están en intimo contacto con la atmósfera ambiental, pero cada día de modo creciente se están empleando grandes bloques y paneles de hormigón prefabricado, además de mármoles y placas calizas en fachadas y elementos vistos de grandes edificios.

Los materiales pétreos, tanto naturales como artificiales, en el medio ambiente de los grandes núcleos urbanos, reaccionan con la atmósfera originando fenómenos de envejecimiento y agresión.

El envejecimiento de una construcción, debido al entorno que le rodea, es una acción que es preciso aceptar "a priori" e incluso ciertos modos de envejecimiento, como antiguas mansiones cubiertas de musgo, nos agradan y lo mismo sucede con el velo de cardenillo, que recubre las estatuas de bronce de una bella pátina verde de sales de cobre.

El hombre y el artista aceptan estas formas de envejecimiento porque la naturaleza nos las impone, y esta naturaleza, por definición, es sabia y rige nuestro desarrollo.

Por el contrario la agresión o corrosión de los materiales en las ciudades industriales es una prueba evidente de la existencia de un medio contaminado, que se considera nocivo, porque atenta contra la naturaleza misma. 
En los momentos actuales en que "el fantasma de la contaminación" ha irrumpido como un nuevo jinete apocalíptico, el individuo de la ciudad se encuentra dominado por un estado de impotencia, sin saber dilucidar si el culpable es la industria, la autoridad pública o la misma sociedad en su concepto vago de expresión. Algunos consideran que la solución del problema se encuentra únicamente en la eliminación de la contaminación; pero aún cuando esta solución sea efectiva, es preciso admitir que la contaminación existe y, que por tanto, desde el punto de vista técnico, los profesionales de la construcción deberían prever este peligro, bien mediante un mejor conocimiento de los materiales de construcción tradicionales o adoptando nuevas formas arquitectónicas.

En esta situación parece conveniente tratar de conocer la atmósfera de los núcleos urbanos y acoplarla a los estudios actuales sobre durabilidad de materiales.

\section{LA ATMOSFERA}

\section{Características generales}

La atmósfera -elemento gaseoso que constituye la capa externa de la Tierra- es el medio en que se realizan las tranformaciones bioquímicas de animales y plantas. Su composición media es $78 \%$ de nitrógeno, $21 \%$ de oxígeno y $1 \%$ de anhídrido carbónico $\mathrm{y}$ gases nobles.

Las atmósferas contaminadas contienen una serie de impurezas, tales como compuestos de azufre, óxidos de nitrógeno, cloruros y otros compuestos, que acostumbran a designarse como "componentes minoritarios".

Los cloruros y sulfatos, presentes en la atmósfera, proceden de la evaporación natural de las aguas marinas, arrastrados por las partículas de vapor acuoso, y se encuentran, como el resto de los componentes minoritarios, en estado de "aerosoles", es decir, formando una dispersión coloidal. Esta cualidad favorece su capacidad de reacción química.

En ambientes normales, la acción del viento y de las corrientes térmicas homogeneizan las masas de aire y evitan una concentración excesiva de estos iones en la atmósfera.

Determinados investigadores, como FENN y otros (5), consideran que los productos tóxicos industriales, no han llegado aún a constituir una parte integrante de la capa atmosférica, ya que la mayoría de los iones contaminadores retornan al suelo o sufren un proceso de neutralización por reacción con las partículas sólidas, que se hallan en suspensión en la atmósfera.

El grado de contaminación atmosférica se mide por la cantidad de materia suspendida, que se deposita en forma de hollín y polvo, o que permanece en suspensión como un "aerosol". Su número varía en las atmósferas de las ciudades y en el aire que cubre las montañas o mares (Tabla I).

TABLA I

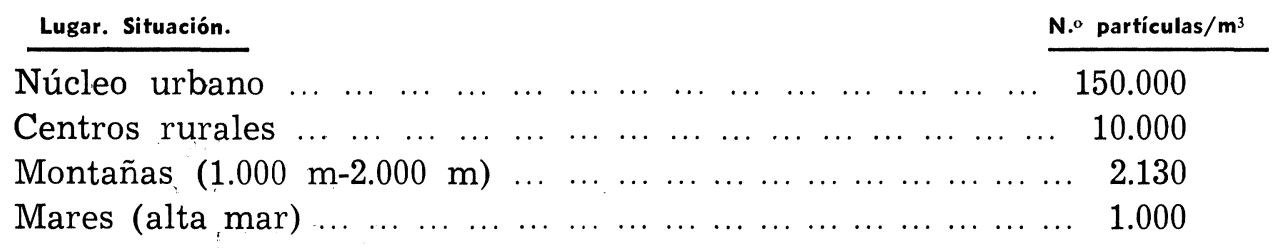

[Datos de JUNGE (6), 1958] 
Como norma general, la cantidad y tamaño de las partículas disminuye con la altura, respecto del suelo, y aumenta con la humedad relativa a igualdad de otras condiciones.

iNfLUENCIA DEL MEDIO AMBieNTE EN LOS MATERIALES DE CONSTRUCCION

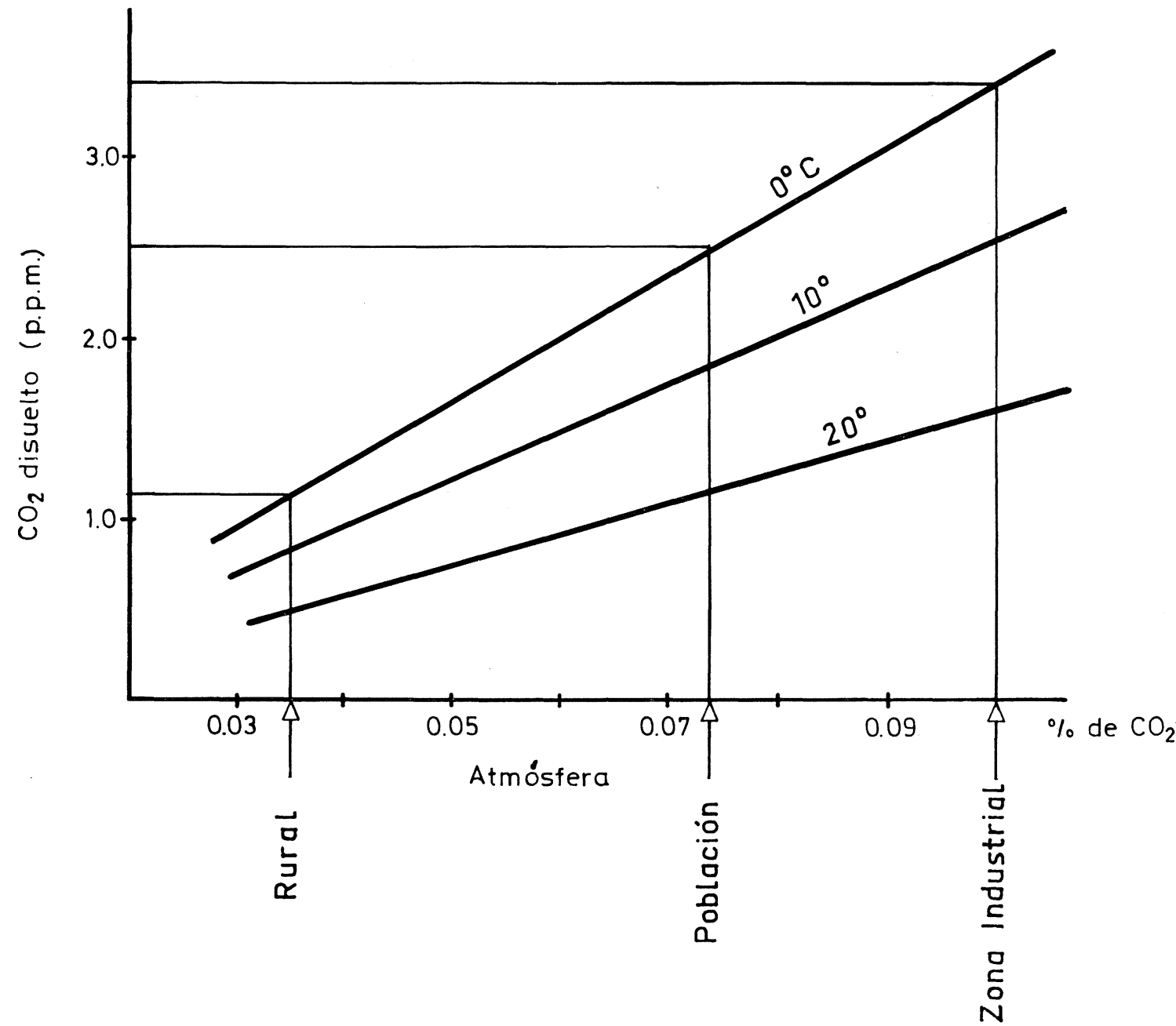

Gráfica 1.-Equilibrio de saturación del $\mathrm{CO}_{2}$ en la atmósfera con el agua.

La acción agresiva que experimentan los materiales de construcción, se debe principalmente al efecto disolvente del agua y a la clase de impurezas que la misma aporte en disolución, como $\mathrm{CO}_{2}$, (dióxido de carbono), $\mathrm{CO}$ (monóxido de carbono), $\mathrm{SO}_{3}$ (trióxido de azufre), $\mathrm{Cl}^{-}$(cloruros) y $\mathrm{NO}_{2}$ (nitratos).

\section{COMPUESTOS QUE EJERCEN ACCION AGRESIVA}

\section{Dióxido de Carbono}

El $\mathrm{CO}_{2}$, también denominado anhídrido carbónico o gas carbónico, siempre se ha considerado como un componente minoritario de la atmósfera terrestre. Su contenido medio suele ser de $0,05 \%$; pero debido al fenómeno de la industrialización su concentración en algunas ciudades llega al $0,27 \%$. 
El incremento se debe a los humos industriales, escape de motores de explosión y a la actividad vital de los seres. Los estudios realizados por BOLIN y ERICKSON en 1959 parecen indicar que las dos fuentes principales son el incremento de industrias y la actividad biosférica.

$\mathrm{CO}_{2}$ procedente del ciclo biosférico

Esta clase de $\mathrm{CO}_{2}$ tiene su origen en los procesos biológicos de la desintegración orgánica y respiración.

Las reacciones de fotosíntesis de los vegetales consumen gran cantidad de $\mathrm{CO}_{2}$ durante las horas diurnas, con producción de oxígeno; pero en las horas nocturnas transcurren en sentido inverso. Por consiguiente, la concentración de $\mathrm{CO}_{2}$ biosférico adquiere su valor máximo durante la madrugada y disminuye durante el día. El valor medio de la concentración de $\mathrm{CO}_{2}$ al nivel del suelo es de 200 a 600 p.p.m. En las zonas muy agrícolas y en las localidades que han transformado prados y pastizales en campos de cultivo intenso, mediante irrigación forzada, este tipo de concentración se incrementa.

$\mathrm{CO}_{2}$ procedente de la industria

Las industrias son las mayores productoras de $\mathrm{CO}_{2}$. Los gases de la combustión de los automóviles representan más del $60 \%$.

El rendimiento de los motores de combustión depende de la relación "combustible/aire": en las ciudades donde los vehículos experimentan continuas paradas y cruces la mezcla se enriquece y se emiten a la atmósfera grandes cantidades de $\mathrm{CO}$ y gases inquemados. Si la combustión es completa se eliminan éstos, pero aumenta la concentración de $\mathrm{CO}_{2}$ y $\mathrm{NO}_{2}$.

Los gases inquemados por acción de la luz del sol se transforman en espesas nieblas, fenómeno muy generalizado en el Valle de la Ciudad de los Angeles en USA.

Los gases nitrogenados, procedentes de la combustión de los hidrocarburos, por acción fotoquímica de la luz solar, originan $\mathrm{NO}_{2}$ y posteriormente ácido nítrico, $\mathrm{NO}_{3} \mathrm{H}$, en contacto del vapor acuoso de la atmósfera, sustancia altamente corrosiva, no sólo por su carácter ácido, sino también por su fuerte acción oxidante.

Durante estos últimos años el nivel de concentración de $\mathrm{CO}_{2}$ en la atmósfera ha aumentado $\mathrm{y}$, se seguirá incrementando, a no ser que se renueven los sistemas de automoción y medios de transporte actuales por vehículos eléctricos y los motores y generadores industriales por generadores nucleares de electricidad.

\section{Monóxido de Carbono}

Procede de la combustión incompleta y se emiten anualmente millones de toneladas.

Este compuesto es altamente nocivo para la vida de los animales y el hombre, ya que hace descender rápidamente el nivel de óxigeno en la sangre, produciendo la muerte por asfixia después de un estado de inconsciencia. El monóxido de carbono no degrada los materiales de construcción de naturaleza pétrea, pero actúa - y este fenómeno es de trascendental importancia- como cataiizador en el proceso de oxidación del anhídrido sulfuroso, $\mathrm{SO}_{2}$, a anhídrido sulfúrico, $\mathrm{SO}_{3}$. 
Existe la evidencia de que este gas desaparece por oxidación bacteriana en el suelo terrestre.

\section{Compuestos de azufre}

La presencia de $\mathrm{SO}_{2}$, anhídrido sulfuroso, en la atmósfera se debe principalmente a la combustión de los carbones y petróleos. Los carbones, que son los mayores contaminantes, disponen de un $8 \%$ de azufre, mientras que el gas natural no sobrepasa el valor de $2 \%$.

Las zonas industrializadas llegan a un consumo medio de una tonelada de carbón por persona y año. Por consiguiente de este dato puede deducirse que se originan $0,6 \mathrm{~kg}$ de ácido sulfúrico por persona y año, cuando la humedad relativa es del $50 \%$, pero se eleva hasta 4,5 kg si la humedad relativa adquiere el valor del $98 \%$.

Los datos anteriores indican que una densidad de población elevada puede producir cantidades considerables de ácido sulfúrico y su efecto nocivo sobre los seres y los materiales es más que conocido.

Las calefacciones de las viviendas y oficinas, durante el invierno, incrementan las concentraciones de estos compuestos a niveles elevados.

$\mathrm{El}$ anhídrido sulfuroso, $\mathrm{SO}_{2}$, puede oxidarse lentamente a anhídrido sulfúrico, $\mathrm{SO}_{3}-\mathrm{com}$ puesto mucho más peligroso- por acción catalítica de la luz solar, acción catalítica que se refuerza por la presencia conjunta de humedad relativa elevada y existencia de monóxido de carbono, $\mathrm{CO}$.

El ataque de los compuestos de azufre a las rocas carbonatadas actúa de dos formas:

1. ${ }^{\circ}$ acción disolvente de los ácidos, y

$2 .^{\circ} \quad$ por acción de sus sales, sulfatos o sulfitos, sobre el carbonato cálcico.

En ambas acciones los carbonatos cálcicos de las rocas carbonatadas se transforman en sulfito y sulfato cálcico.

El sulfito cálcico tiene, aproximadamente, la misma solubilidad que la calcita, $\mathrm{CO}_{3} \mathrm{Ca}$, en agua pura, pero no está influenciada por la temperatura ni por el contenido de $\mathrm{CO}_{2}$. El sulfato cálcico es mucho más soluble que ambos e incluso el sulfato magnésico lo es más que el yeso.

Las reacciones que realizan los sulfatos sobre las rocas silicatadas no están estudiadas a fondo, pero probablemente esta acción está íntimamente relacionada con los fenómenos de caolinización.

Las bacterias sulfáticas aerobias participan también en los procesos antes mencionados.

\section{Cloruros}

El ion cloruro es un constituyente importante de la atmósfera. Procede del mar, del desierto y de las industrias.

Los cloruros presentes en la atmósfera, por acción catalítica pueden transformarse en ácido clorhídrico, que disuelve rápidamente los compuestos carbonatados de las rocas. 


\section{Nitratos}

Los nitratos, generalmente expresados analíticamente como $\mathrm{NO}_{2}$, se encuentran uniformemente distribuidos por la atmósfera, en una concentración de 2 a 4 microgramos por $\mathrm{m}^{3}$ pero se registran concentraciones más elevadas en las zonas urbanas e industriales, hasta 400 microgramos $/ \mathrm{m}^{3}$.

La combustión completa es un factor contribuyente en la emisión de óxidos de nitrógeno a la atmósfera. La transformación en ácido nítrico es normal en las nieblas fotoquímicas, antes mencionadas.

\section{LAS AGUAS PRocedentes de PRECipitaciones atMosfericas}

\section{Las lluvias}

La composición química del agua de lluvia está íntimamente ligada con la atmósfera local de que procede, y su acción agresiva química se debe a los iones captados durante su recorrido entre la nube y el suelo.

Los investigadores WHITHEAD y FETH (7) distinguen entre los conceptos: "lluvia seca", "lluvia" y "precipitación".

La "lluvia" está constituida por gotas de agua y partículas sólidas en suspensión, procedentes de las zonas bajas de la atmósfera, captadas durante su trayectoria.

La "lluvia seca" está integrada por el conjunto de partículas sólidas, procedentes de las capas bajas de la atmósfera, que no han sido captadas por las gotas de lluvia pero que caen a tierra junto con ellas.

Por "precipitación" se entiende el conjunto de las dos anteriores.

Los compuestos detectados en el agua de lluvia, mediante su análisis químico, indican con bastante claridad la atmósfera de donde proceden, y su indudable origen marino, cuando esta sea su procedencia. Las partículas secas nos reflejan la naturaleza del polvo ambiental.

En aquellas regiones o zonas en que el aire contiene $\mathrm{CO}_{2}$ y $\mathrm{SO}_{3}$ en cantidad excesiva, la lluvia puede llegar a tener un carácter fuertemente ácido y ser altamente corrosiva no sólo para las piedras, sino también para los metales.

\section{El contenido de $\mathrm{CO}_{2}$ en las aguas de lluvia}

El agua fría disuelve más cantidad de $\mathrm{CO}_{2}$ que a la temperatura ambiente, así a la temperatura de $0^{\circ} \mathrm{C}$ disuelve doble cantidad que a $25^{\circ} \mathrm{C}$. En la gráfica 1, tomada del investigador NORDELL (8), se han dispuesto en abscisas los contenidos de $\mathrm{CO}_{2}$ con expresión de aquéllos aproximados a los ambientes rurales, ciudadanos e industriales, y en ordenadas las solubilidades del $\mathrm{CO}_{2}$ en el agua.

El contenido de $\mathrm{CO}_{2}$ disponible en el agua influye extraordinariamente en la solubilidad de los carbonatos y acelera la descomposición de las rocas silíceas. 
BICZOK (4), hace un estudio bastante profundo del comportamiento de los materiales de hormigón frente a la acción agresiva del $\mathrm{CO}_{2}$ contenido en las aguas. Indica de forma terminante que en las zonas fabriles e industriales los humos se mezclan con el vapor y la niebla durante un espacio de tiempo bastante largo y posteriormente se depositan en la superficie de los materiales.

También se indica que las superficies de hormigón de los pedestales de las estatuas y en las molduras que no posean una excesiva pendiente, se observa con frecuencia una corrosión superficial, si dichas superficies permanecen durante bastante tiempo en contacto con las aguas de lluvia que contienen ácido carbónico.

La corrosión que produce el $\mathrm{CO}_{2}$ en el hormigón es tan peculiar que este mismo investigador tras indicar que presenta rasgos propios, la cataloga o clasifica como un tipo de corrosión independiente.

\section{Los contenidos de $\mathrm{SO}_{4}{ }^{2-}$ y $\mathrm{Cl}^{-}$en el agua de lluvia}

Las aguas de lluvia que contienen cualquiera de estos iones o ambos a la vez, constituyen un serio peligro desde el punto de acción corrosiva sobre las piedras y el hormigón.

En las zonas no contaminadas de ambiente marino ambos iones aparecen en las aguas de lluvia, procentes de la evaporación y arrastre de las aguas del mar, así como en las zonas desérticas. En las regiones industrializadas llegan a sobrepasar las concentraciones permisibles.

En USA y concretamente en la Región de los Grandes Lagos se ha podido comprobar que las aguas de los lagos Erie, Ontario y Michigan han duplicado su contenido en estos iones durante los últimos diez años, debido a las aportaciones de aguas industriales. El efecto producido por estas aguas ha sido alterar los suelos y las rocas puestas en contacto. La velocidad de este aumento iónico debe servir de aviso al daño que las aguas contaminadas pueden hacer en los materiales pétreos.

\section{Acción neutralizante de los polvos sobre las lluvias}

El polvo de origen natural suele estar constituido por partículas materiales, con tamaños comprendidos entre 1 y 100 micras. Proceden de residuos terrestres arrastrados por el viento, de origen volcánico y, finalmente, de origen cósmico extraterrestre.

El polvo que se encuentra en suspensión en las capas bajas de la atmósfera se elimina por las gotas de lluvia, aunque algo del mismo se dispone entre las gotas que caen, como se ha explicado anteriormente, y constituye la denominada "lluvia seca".

Polvo arrastrado por el viento

Las partículas suelen ser de tamaño pequeño y su origen se encuentra en las playas y depósitos de los ríos en la época de estiaje. Algunas veces proceden de los campos arados en grandes zonas rurales y de las grandes construcciones y obras civiles.

Los polvos de naturaleza caliza reaccionan fácilmente con los ácidos presentes en el agua de lluvia. La caliza convierte a los iones sulfito y sulfato en yeso, cuya acción es bastante menos dañina. 
El yeso que contienen las aguas de lluvia no es nocivo para el hombre, sin embargo, es proverbial la acción de las aguas selenitosas sobre los hormigones, tanto en masa como armados. SUMI, CORKERY y MONKMAN (9) interpretan que la solubilidad del yeso en el agua (2 g/litro), explica el relativamente alto contenido de ion calcio en las aguas de lluvia.

Por lo que respecta al grado de acidez de la lluvia en un futuro, parece ser que frente a su mayor acidez, debido a una superior contaminación, se opondrá su mayor contenido de polvos con acción neutralizante, con lo cual se cumplirá una vez más la Ley del Equilibrio en la naturaleza.

El polvo de origen volcánico

Las erupciones explosivas de los volcanes producen un polvo, constituido principalmente por vidrios silicatados, que queda en suspensión durante muchos años en las capas altas de la atmósfera. Este polvo viaja durante esa época, acabando por depositarse otra vez sobre el suelo.

Parece ser que su acción no se considera perjudicial.

Polvo de origen cósmico

Se encuentran en los sedimentos marinos de mucha edad geológica y suelen ser pequeñas pepitas de hierro metálico o incluso vidrios silicatados. Sus características químicas inactivas y su exigua cantidad hacen que su acción sea nula.

\section{B I B L I O G R A F I A}

(1) A. Steopoe: La Durabilité du Beton. Ed. Eyrolles; París (1970).

(2) H. KÜHL: Zement Chemie. Verlag Technik; Berlín (1952).

(3) Coloquio Rilem. Praga, (1961).

(4) BIczok: Betonkorrosion Betonschutz. Akadémiai Kiadó; Budapest, (1968).

(5) R. W. FenN, H. F. GERber y D. WASShausen: Journal Atmospheric Science, (1963).

(6) C. E. Junge: Atmospheric Chemistry. Academic Press, (1958).

(7) H. C. Whithead y J. F. Feth: Journal Geophisical Research, (1969).

(8) E. NoRDELL: Water treatment for industrial and other uses. Ed. Reinhold; New York, (1951).

(9) L. A. SumI: American Geophysic Union. Monografía n. ${ }^{\circ}$ 3, (1959). 